\title{
Biological and Chemical Characterizations of Allelopathic Potential of Diverse Accessions of the Cover Crop Sunn Hemp
}

\author{
Muhammad Mansoor Javaid \\ Department of Agronomy, University College of Agriculture, University of Sargodha, Pakistan \\ Manish Bhan \\ Department of Physics and Agrometeorology, Jawaharlal Nehru Agricultural University, Jabalpur \\ 482004, India
}

Jodie V. Johnson

Mass Spectrometry Facility, Department of Chemistry, University of Florida, Gainesville, FL 32611-7200

\author{
Bala Rathinasabapathi and Carlene A. Chase ${ }^{1}$ \\ Horticultural Sciences Department, University of Florida, Gainesville, FL 32611-0690
}

\begin{abstract}
AdDitional INDEX words. allelopathy, lettuce bioassay, phytotoxicity, legume, weed control, hydroxynorleucine
Aвstract. There has been increasing interest in recent years in sunn hemp (Crotalaria juncea), as a leguminous cover crop and green manure, for weed and pest management and improving soil health. Aqueous extracts and ground shoot tissue have previously been demonstrated to be phytotoxic. To further explore its allelopathic potential, bioassays and chemical characterization of water-soluble eluates of sunn hemp were undertaken. Lettuce (Lactuca sativa) radicle growth inhibition was conducted with aqueous eluates from thinly sliced sunn hemp leaves, stems, and seeds, and all three tissues exhibited the inhibitory potential. Fourteen accessions originating from the United States, India, Brazil, South Africa, Pakistan, and Nigeria had water-soluble allelochemicals in leaves, suggesting that allelopathic potential is widely distributed in this species. The highest level of inhibitory potential was found in accession IN-86. Further characterization of IN-86 leaf eluates indicated that the inhibitory compound(s) was/were not soluble in chloroform, but was/were stable when boiled for 15 minutes and resistant to 1 N HCl. Binding and elution from $\mathrm{AG}-1\left(\mathrm{OH}^{-}\right)$ion-exchange resin also were observed. An analysis of leaf eluates of IN-86 using highperformance liquid chromatography (HPLC) followed by mass spectrometry (MS) showed the presence of a compound with a mass-to-charge ratio of 148, consistent with the spectrum for hydroxynorleucine, a phytotoxic nonprotein amino acid previously reported in seeds of $C$. juncea. However, its low concentration $\left(<1 \mu \mathrm{g} \cdot \mathrm{mL}^{-1}\right)$ suggested that other components of the eluate were responsible for the observed allelopathic effect. The results indicate the feasibility for development of weed control strategies using allelochemicals derived from sunn hemp biomass of select genotypes IN-86, NG-71, and BR-20 from India, Nigeria, and Brazil, respectively.
\end{abstract}

Sunn hemp, a multipurpose species used for fiber, fodder, and biomass (Cook and White, 1996), is widely grown in tropical and subtropical agricultural systems for its usefulness as a cover crop and green manure. A cover crop of sunn hemp can provide sufficient dry matter to protect the soil from erosion and add substantial amounts of nitrogen in its residues (up to $\approx 126 \mathrm{~kg} \cdot \mathrm{ha}^{-1}$ ) for use by the subsequent crop (Mansoer et al., 1997). In addition to these benefits, sunn hemp competes effectively with weeds (Collins et al., 2007, 2008), making it especially useful for weed management in organic and sustainable production of row crops. A nonprotein amino acid deltahydroxynorleucine was identified in sunn hemp seeds (Pant and Fales, 1974; Pilbeam and Bell, 1979) that was demonstrated to be phytotoxic, inhibiting hypocotyl and radicle growth during germination (Wilson and Bell, 1979). Nonprotein amino acids

Received for publication 24 June 2015. Accepted for publication 26 Aug. 2015. This work was supported by a grant from USDA Southern Sustainable Agriculture Research and Education program grant number LS08-205. M. Mansoor Javaid was supported by a scholarship from the Higher Education Commission, Pakistan. ${ }^{1}$ Corresponding author. E-mail: cachase@ufl.edu. from other legumes also have been shown to be phytotoxic. These include L-3-(3,4-dihydroxyphenyl)alanine (L-DOPA) from velvet bean [Mucuna pruriens var. utilis (Nishihara et al., 2005)], mimosine and albizziine from Leucaena leucocephala and Albizia species, respectively (Williams and Hoagland, 2007), and m-tyrosine from Festuca species (Bertin et al., 2009). Cole (1991) found that extracts of sunn hemp seeds reduced the growth of several weeds. Aqueous extracts of leaves also showed inhibitory effects on the roots of wheat seedlings [Triticum aestivum (Ohdan et al., 1995)] and extracts from macerated sunn hemp leaves and leachate from whole sunn hemp leaves inhibited maize (Zea mays) germination at $15 \%$ and $30 \% \mathrm{w} / \mathrm{v}$ (Cruz-Silva et al., 2015).

Because of the potential to use sunn hemp's allelopathic properties for weed suppression in horticultural crop production systems, we examined the phytotoxicity of its aqueous foliar extracts and ground, dried residues in an earlier study (Adler and Chase, 2007). Both sunn hemp extracts and ground, dried residues inhibited the germination and growth of livid amaranth (Amaranthus lividus), goosegrass (Eleusine indica), bell pepper (Capsicum annuum), and tomato (Solanum lycopersicum) 
germination with greater negative effects on livid amaranth than in other species (Adler and Chase, 2007). Skinner et al. (2012) reported that ground, dried sunn hemp residues inhibited germination of lettuce and smooth pigweed (Amaranthus hybridus), and aqueous leaf extracts reduced germination and seedling growth of various crops. Despite this progress, several aspects of allelopathy by sunn hemp are not well understood. Sunn hemp has considerable genetic diversity (Wang et al., 2006), but possible differences in allelopathic potential of different accessions and the nature and properties of the allelochemicals are not known. The objectives of the current study were to test the relative allelopathic potential of leaves, stems, and seeds of a commercially available sunn hemp cultivar and to evaluate the allelopathic potential of aqueous leaf eluates from 14 accessions from eight countries. In addition, we examined whether the phytotoxic compounddelta-hydroxynorleucine-was the major allelochemical in sunn hemp aqueous leaf eluate.

\section{Materials and Methods}

Plant material used. Leaves and stems from a commercially available sunn hemp cultivar (Kauffman Seeds, Haven, KS) were used immediately after harvest from 3-month-old plants grown in a field in Gainesville, FL, with overhead irrigation during Fall 2011. Since the provenance of this seed source was unknown, a voucher specimen of the plant Rathinasabapathi 1 (FLAS) was submitted to the Florida Museum of Natural History in Gainesville, FL. In the experiment in which 14 different sunn hemp accessions [U.S. Department of Agriculture, Agricultural Research Service, Griffin, GA (Table 1)] were screened, plants were grown one per 11.4-L container in potting medium (Fafard no. 2; Sun Gro Horticulture, Agawam, MA) in a greenhouse with mean maximum and minimum temperatures of 27 and $20^{\circ} \mathrm{C}$, respectively, during Fall 2011. The plants were fertilized with a commercial fertilizer $(20 \mathrm{~N}-8.7 \mathrm{P}-16.6 \mathrm{~K})$, irrigated manually once per week, and the leaves were harvested before flowering.

Table 1. Aqueous eluates from stem, leaf, and root sections of 14 sunn hemp accessions were evaluated for phytotoxicity in bioassays with the lettuce cultivar Green Ice.

\begin{tabular}{lcll}
\hline Accession & USDA PI no. $^{z}$ & Other names $^{\mathrm{y}}$ & \multicolumn{1}{c}{ Origin } \\
\hline US-56 & PI 468956 & Tropic Sun & United States \\
IN-87 & PI 250487 & K681 & India \\
BR-77 & PI 322377 & IRI 2473 & Brazil \\
FS-39 & PI 314239 & No 524 & former Soviet Union \\
BR-80 & PI 337080 & n.a. & Brazil \\
US-39 & PI 652939 & 374 & Texas, United States \\
SA-67 & PI 391567 & T'ai-yang-ma & South Africa \\
PK-26 & PI 426626 & Sanni, K-98 & Pakistan \\
IN-86 & PI 250486 & K680 & India \\
IN-85 & PI 250485 & K679 & India \\
NG-71 & PI 234771 & n.a. & Nigeria \\
BR-20 & PI 561720 & IAC-1 & Brazil \\
SR-57 & PI 207657 & n.a. & Sri Lanka \\
IN-97 & PI 346297 & n.a. & Delhi, India \\
\hline
\end{tabular}

zUnited States Department of Agriculture's Plant Introduction Number.

${ }^{y}$ Local names, cultivar name, or other designation associated with accessions; n.a. indicates that information is not available.
Bionssay for allelopathic potential. A lettuce bioassay for allelopathy using surface-sterilized seeds of cultivar Green Ice (Park Seed, Greenwood, SC) was conducted as described in Ferguson et al. (2004). Briefly, $5 \mathrm{~g}$ fresh weight of plant tissue of each of the various accessions cut into 1-cm strips were incubated in $50 \mathrm{~mL}$ of water for $24 \mathrm{~h}$, the aqueous fraction filtered with four layers of cheesecloth, centrifuged at $300 \mathrm{~g}_{\mathrm{n}}$ for $10 \mathrm{~min}$, filtered using a $0.2-\mu \mathrm{m}$ filter, and stored at $6^{\circ} \mathrm{C}$ until use. It is to be noted that this relatively gentle method of elution preferentially elutes watersoluble phytochemicals only and elutes about $10 \%$ of the phytochemicals in the tissue compared with a typical phytochemical extraction where the tissue is macerated in a solvent (Ferguson et al., 2004; Rathinasabapathi et al., 2005). No visual signs of microbial growth could be observed in these eluates after the 24-h incubation. Lettuce seeds were surface sterilized by washing in $10 \%(\mathrm{v} / \mathrm{v})$ commercial bleach and rinsed five times in sterile water. At least 20 surface-sterilized lettuce seeds were used in each bioassay. Three milliliters of eluates per test were used on a Whatman no. 2 filter paper (GE Healthcare BioSciences, Pittsburgh, PA) placed in a petri dish. Seed germination was assessed and radicle lengths after were measured following after 24- and 72-h incubation, respectively, under a light bench $\left[16 / 8 \mathrm{~h}\right.$ (light/dark), $\left.150 \mu \mathrm{mol} \cdot \mathrm{m}^{-2} \cdot \mathrm{s}^{-1}\right]$.

TESTS ON STABILITY AND CHEMICAL NATURE OF PнутоснемicALs. Leaf eluates of sunn hemp accession IN-86 were used. For testing stability to heat, the eluate was boiled at $100{ }^{\circ} \mathrm{C}$ for $15 \mathrm{~min}$. Acid stability was tested by hydrolyzing the
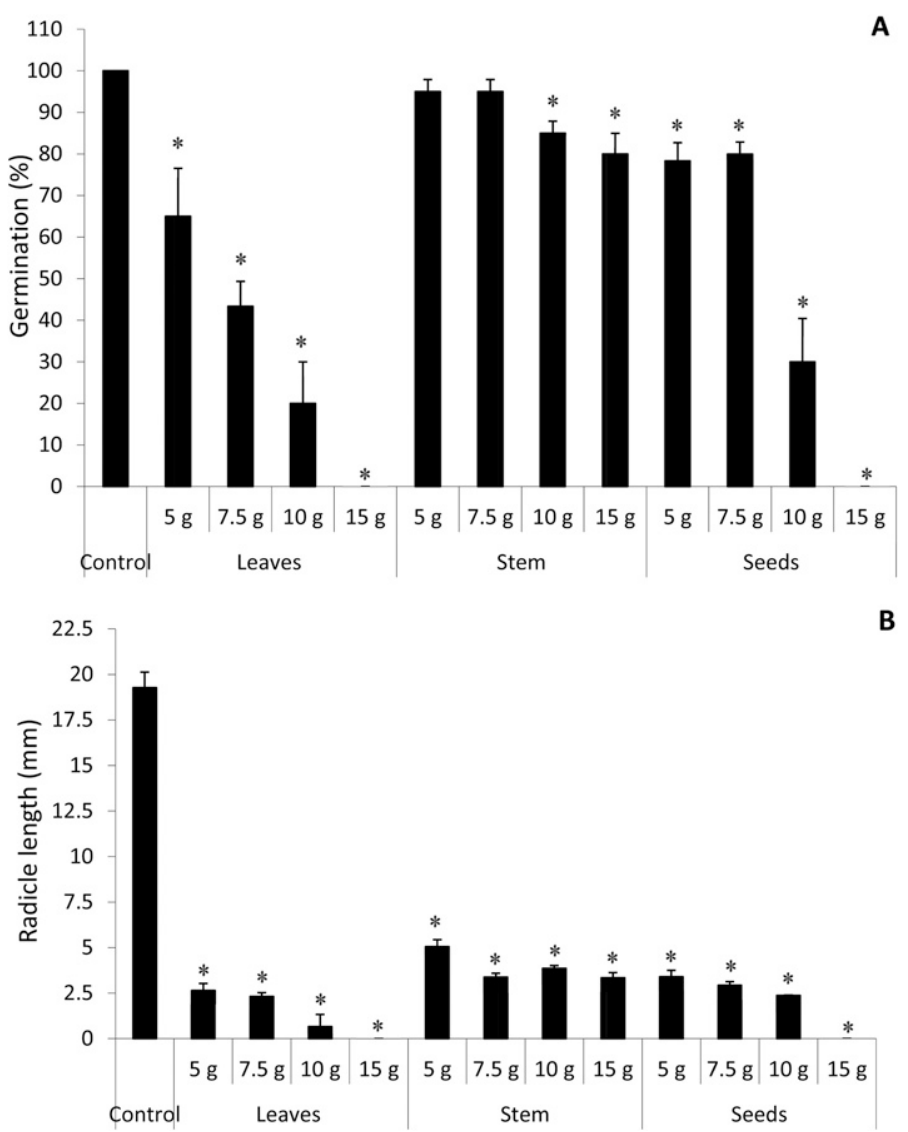

Fig. 1. Inhibition of (A) lettuce seed germination and (B) lettuce radicle elongation by aqueous eluates from a commercially available sunn hemp cultivar. Bars show means and SE for observations on at least 15 lettuce seedlings. Bars marked by an asterisk indicate significant difference at $P \leq 0.05$ compared with the control determined using Fisher's protected least significant difference test. 
eluate in $1 \mathrm{~N} \mathrm{HCl}$ for $15 \mathrm{~min}$ at $50^{\circ} \mathrm{C}$. Then $\mathrm{HCl}$ was evaporated in a nitrogen evaporator and the residue was redissolved in water and $\mathrm{pH}$ was adjusted to 7 as needed before testing. A negative control was included that contained $\mathrm{HCl}$, but no eluate, which provided results similar to a water control (data not shown). For a solubility test, aqueous eluate $(3 \mathrm{~mL})$ was extracted with an equal volume of chloroform and the aqueous and organic phases were separated and evaporated and residues were redissolved in water. To test the ionic nature of the compounds, an aliquot of leaf eluate $(7 \mathrm{~mL})$ was passed through 1.5-mL columns of $\mathrm{AG}-1(\mathrm{OH}-)$ and $\mathrm{AG}-50(\mathrm{H}+)$ ion-exchange resins, placed in tandem, the anion exchange column above the cation exchange column (Bio-Rad, Hercules, CA). The unbound fractions were collected and the columns were eluted with $15 \mathrm{~mL}$ of $0.1 \mathrm{~N} \mathrm{HCl}$ followed by $15 \mathrm{~mL}$ of $2.5 \mathrm{~N} \mathrm{HCl}$. The liquid was evaporated using a stream of air and residues were redissolved in $5 \mathrm{~mL}$ water. All treated (temperature, acid, and ion exchange) fractions were tested for bioactivity using the lettuce bioassay described above.

ANALYSES OF LEAF ElUATES FOR PHYTOCHEMicals. Leaf eluates (with or without ion-exchange purification) were analyzed using HPLC (Agilent Technologies, Santa Clara, CA) equipped with a 1100 series binary pump, fitted with a $2 \times 150-\mathrm{mm}$ column (Synergi $4 \mu$ Hydro-RP80A, serial no. 106273-5; Phenomenex, Torrance, CA). The mobile phase consisted of an isocratic gradient of solvents A $(0.2 \%$ acetic
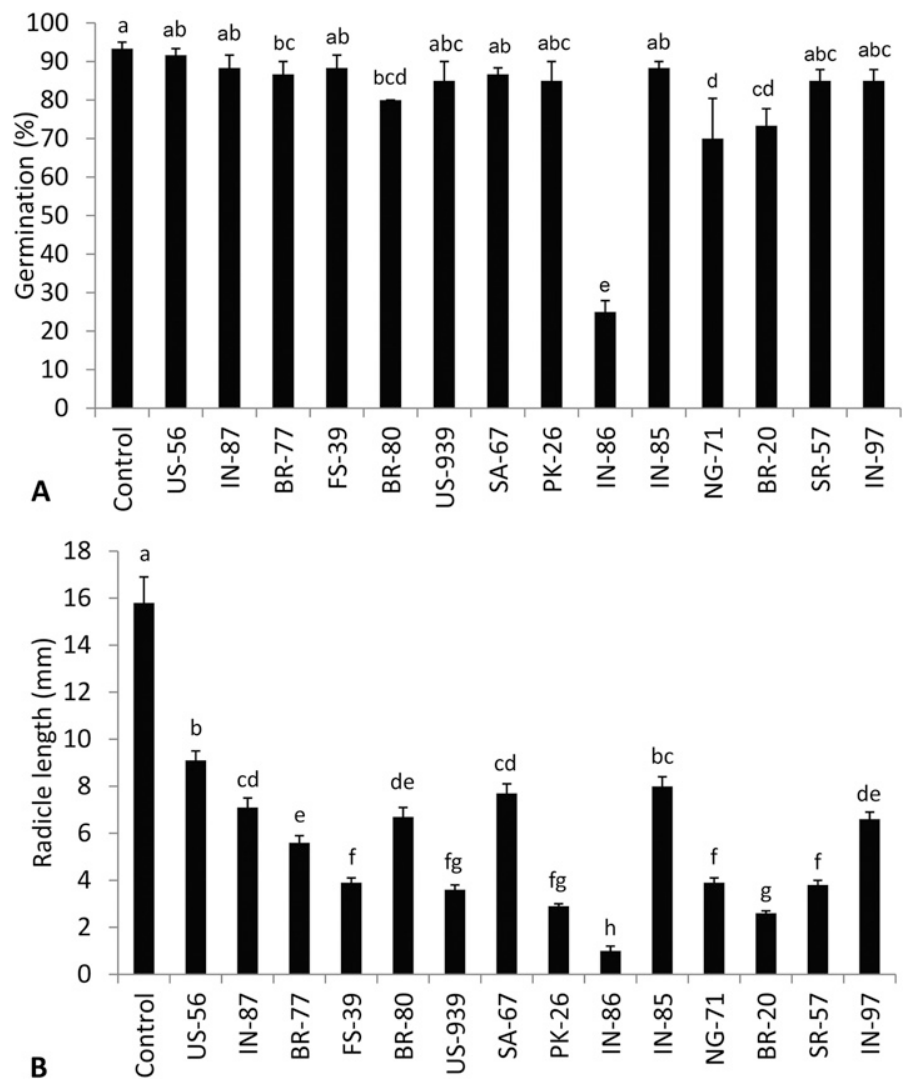

Fig. 2. Aqueous eluates from the leaves of 14 sunn hemp accessions showed allelopathic potential when (A) seed germination and (B) radicle elongation were assessed in bioassays with 'Green Ice' lettuce. Bars illustrate means and SE for observations on at least 15 lettuce seedlings. Bars marked by different letters indicate significant difference at $P \leq 0.05$ determined using Fisher's protected least significant difference test. acid in water) and $\mathrm{B}(0.2 \%$ acetic acid in methanol) at $0.15 \mathrm{~mL} \cdot \mathrm{min}^{-1}$. The peaks were detected using an ultraviolet/ visible (ultraviolet/Vis) detector (1100 G1314A; Agilent Technologies) at $230 \mathrm{~nm}$. Mass spectral analyses were performed using a mass spectrometer (Thermo-Finnigan; Thermo Fisher Scientific, Waltham, MA) with electrospray ionization [ESI (sheath gas nitrogen)] at a heated capillary temperature of $250{ }^{\circ} \mathrm{C}$. The $(+)$ ESI spray voltage was $3.3 \mathrm{kV}$ at heated capillary voltage of $12.5 \mathrm{~V}$ and (-)ESI spray voltage was $3.2 \mathrm{kV}$ at a heated capillary voltage of $10 \mathrm{~V}$.

ESTIMATION OF DELTA-HYDROXYNORLEUCINE. A standard of L-6-hydroxynorleucine (formula weight 147.17; ChemSamp Co., Dallas, TX) was used to quantify delta-hydroxynorleucine in leaf eluates of accession IN-86 using HPLC-MS-MS equipment and the method described above.
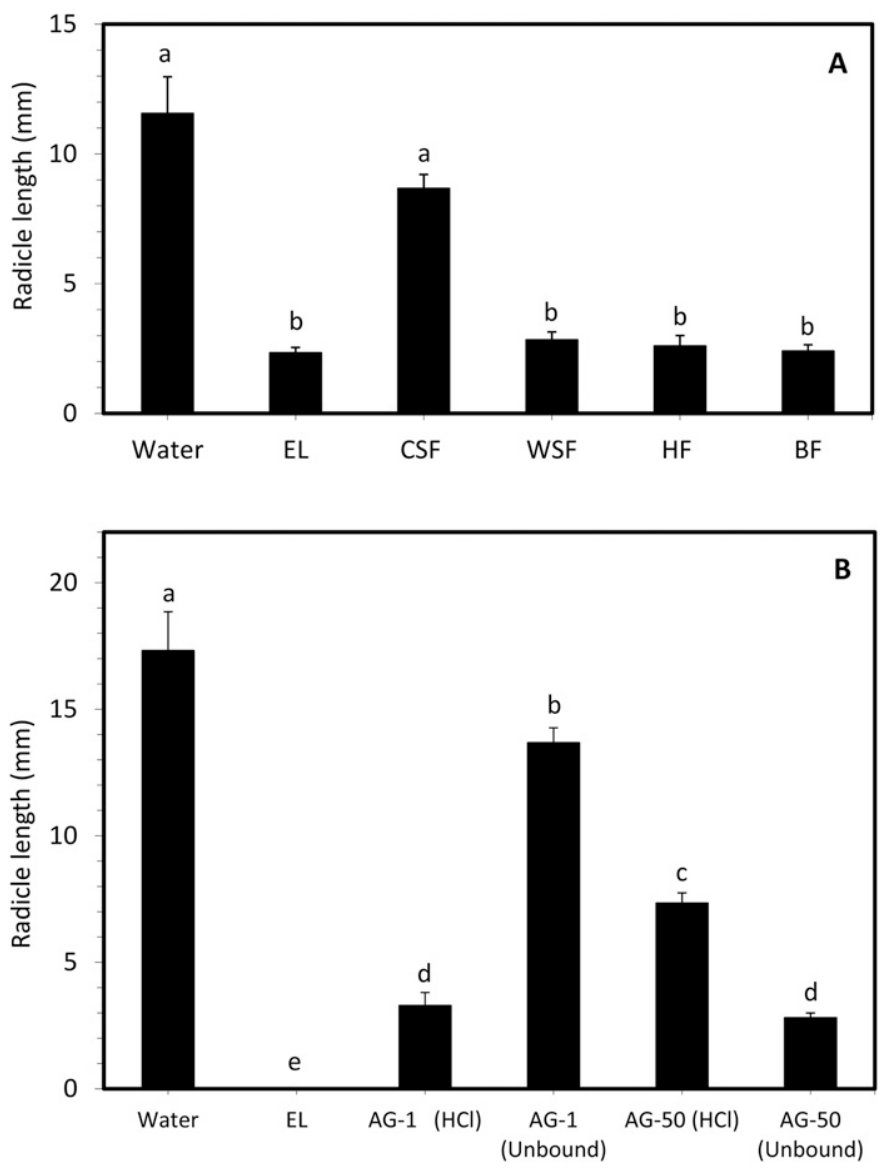

Fig. 3. Assessment of solubility and stability characteristics of putative allelochemicals in leaf eluates from sunn hemp accession IN-86. Bars represent means and SE for observations on at least 15 seedlings each. Bars marked by different letters indicate significant difference at $P \leq 0.05$ determined using Fisher's protected least significant difference test. (A) water (control), EL (eluate), CSF (chloroform-soluble fraction, chloroform evaporated, redissolved in water), WSF (water-soluble fraction left after removal of chloroform phase), $\mathrm{HF}$ (hydrolyzed fraction, eluate treated with $1 \mathrm{~N} \mathrm{HCl}$, $50{ }^{\circ} \mathrm{C}$ for $15 \mathrm{~min}, \mathrm{HCl}$ evaporated, redissolved in water), $\mathrm{BF}$ (eluate boiled at $100{ }^{\circ} \mathrm{C}$ for $15 \mathrm{~min}$ ). (B) Ion-exchange purified fractions: water (control); EL (eluate); $\mathrm{AG}-1(\mathrm{HCl})$ [eluate loaded on $1.5 \mathrm{~mL} \mathrm{AG-1}\left(\mathrm{OH}^{-}\right)$resin, unbound washed with water, column eluated in $2.5 \mathrm{~N} \mathrm{HCl}, \mathrm{HCl}$ evaporated and redissolved in water]; AG-1 (Unbound) [eluate from $\mathrm{AG}-1\left(\mathrm{OH}^{-}\right)$column as unbound]; AG-50 [eluate loaded on $1 \mathrm{~mL} \mathrm{AG-50}\left(\mathrm{H}^{+}\right)$resin, unbound washed with water, column eluted in $2.5 \mathrm{~N} \mathrm{HCl}, \mathrm{HCl}$ evaporated and redissolved in water]; $\mathrm{AG}-50$ (Unbound) [fraction that did not bind to either $\mathrm{AG}-1\left(\mathrm{OH}^{-}\right)$or $\mathrm{AG}-50\left(\mathrm{H}^{+}\right)$resin]. 
STATISTICS. Analysis of variance of quantitative data were performed using the general linear models procedure of SAS (version 9.2; SAS Institute, Cary, NC) and mean comparisons were performed using Fisher's least significant difference test at $\alpha=0.05$.

\section{Results}

Allelopathic potential. When aqueous eluates of leaves, stem, and seeds of the commercial sunn hemp cultivar were evaluated, it was found that lettuce seed germination and radicle growth were negatively affected in a concentrationdependent manner (Fig. $1 \mathrm{~A}$ and B). As $10 \mathrm{~g}$ tissue in $50 \mathrm{~mL}$ water was sufficient to inhibit germination and root growth, additional experiments were performed using this ratio of tissue to water. Leaf eluates from 14 sunn hemp accessions grown under uniform conditions were compared using the lettuce bioassay for allelopathic potential. Leaf eluates of accessions BR-77, BR-80, IN-86, NG-71, and BR-20 significantly ( $P \leq$ $0.05)$ inhibited lettuce seed germination compared with the water control (Fig. 2A). Eluates from all 14 accessions $(P \leq$ $0.05)$ inhibited radicle growth and the eluate from IN-86 resulted in the greatest inhibition (Fig. 2B).

Stability AND CHEMical Nature of allelochemicals. To evaluate sunn hemp allelochemicals for amenability to procedures that may be needed for development of a bioherbicide, leaf eluates of IN-86 were subjected to chloroform partitioning, acid hydrolysis, boiling, and ion-exchange chromatography. Figure $3 \mathrm{~A}$ shows that allelopathic compounds are not present in the chloroform fraction (CSF) following phase separation with an aqueous eluate. Sunn hemp allelochemicals also were stable to limited acid hydrolysis and boiling. In a test using ion-exchange resins, the inhibitory compounds were effectively bound to AG-1 (OH-) but were only partially bound by AG-50 $(\mathrm{H}+)$, suggesting that the majority of allelochemicals were either negatively charged or had no charge (zwitterionic) (Fig. 3B).

ANALySes of Leaf eluates fOR PUTATIVE allelochemicals. Ion-exchange resin-purified fractions had at least 12 ultravioletpositive peaks each eluting within the first $35 \mathrm{~min}$ of the gradient (Fig. 4). More than $70 \%$ of the peaks were eluted within the first 8 min of the run. HPLC/ultraviolet/(+)ESI-MS ${ }^{\mathrm{n}}$ analysis identified the presence of protonated compounds with $(\mathrm{m} / \mathrm{z}) 178.6,132.0,153.2,166.0,260.8,422.9,534.0,758.6$, 205.0, 158.1, 406.5, 422.0, 209.0, 190.8, 236.8, 287.3, 285.2, 291.3, 293.1, 293.2, 353.3, 295.2, 277.3, 268.9, 268.9, 376.3, $618.2,465.1,449.1,595.2,625.1,463.2,617.1,433.0,529.5$ $695.3,699.3,663.3,514.8,432.8,514.8,959.2,874.4,858.3$, 773.0, 757.0, 826.3, 840.2, 933.0, 1211.1, 1179.0, 997.0, 695.3,

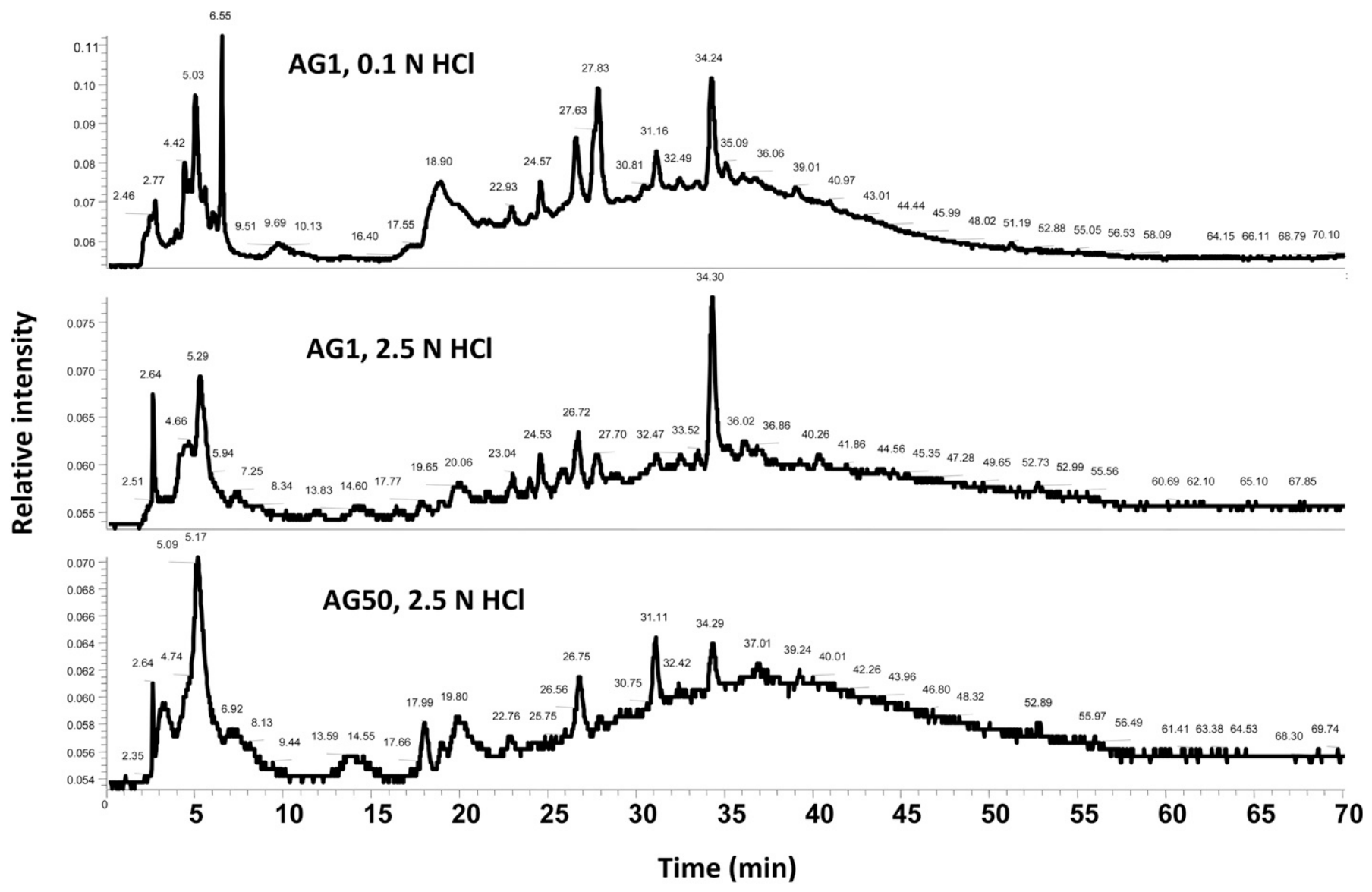

Fig. 4. Distribution of ultraviolet-positive phytochemicals in sunn hemp leaf eluate. Leaf eluates of sunn hemp accession IN-86 were fractionated using ionexchange resins and eluted using different strengths of $\mathrm{HCl}$. After evaporation of $\mathrm{HCl}$, the compounds were dissolved in water and separated using highperformance liquid chromatography. The ion-exchange fractions were from $\mathrm{AG}-1(\mathrm{OH}-)$ with $0.1 \mathrm{~N} \mathrm{HCl}(\mathrm{AG}-1,0.1 \mathrm{~N} \mathrm{HCl}), \mathrm{AG}-1(\mathrm{OH}-)$ eluted with $2.5 \mathrm{~N} \mathrm{HCl}$ $(\mathrm{AG}-1,2.5 \mathrm{~N} \mathrm{HCl})$ and $\mathrm{AG}-50(\mathrm{H}+)$ resin eluted with $2.5 \mathrm{~N} \mathrm{HCl}(\mathrm{AG}-50,2.5 \mathrm{~N} \mathrm{HCl})$. Peaks detected at $230 \mathrm{~nm}$ in a gradient high-performance chromatograph are shown with retention time marked on the peaks. 
and 695.4 in the leaf eluate (Fig. 5). HPLC/ultraviolet/(-)ESI-MS ${ }^{\text {n }}$ analysis identified the presence of compounds with $(\mathrm{m} / \mathrm{z}) 191.1$, 167.3, 164.3, 343.1, 421.1, 443.0, 763.4, 327.4, 593.2, 577.2, $677.4,771.3$, and 755.3 in the leaf eluate (data not shown). A comparative analysis of mass spectral data from both (-)ESI and $(+)$ ESI modes confirmed molecular weights for 65 compounds (Table 2).

Because of the unavailability of standard delta-hydroxynorleucine, 6-hydroxynorleucine was used for quantifying delta-hydroxynorleucine in a leaf eluate of IN-86. With (+) ESIMS, 6-hydroxynorleucine produced $\mathrm{m} / \mathrm{z} 148[\mathrm{M}+\mathrm{H}]+$ ions, which dissociated to form $(\mathrm{m} / \mathrm{z}) 130$ and 102 product ions (Fig. 6). The standard showed acceptable linearity between 50 and $5000 \mathrm{pg} \cdot \mathrm{mL}^{-1}$, when estimated at $(\mathrm{m} / \mathrm{z})$ 148, 130, or 102 (data not shown). Because of the absence of interferences, the product ion $\mathrm{m} / \mathrm{z} 102$ was used for quantitative estimation of hydroxynorleucine. On the basis of four analyses, the leaf eluate had $892 \mathrm{ng} \cdot \mathrm{mL}^{-1}$, with $15 \%$ relative standard deviation.

\section{Discussion}

The allelopathic potential of sunn hemp tissues of multiple sunn hemp genotypes from various countries was consistent with the results for individual genotypes tested in previous studies (Adler and Chase, 2007; Ohdan et al., 1995; Skinner et al., 2012). The current study further expanded upon previous work to show that water-soluble allelochemicals are present in seeds, leaves, and stems of sunn hemp, and that stems had the lowest allelopathic potential of the three organs (Figs. 1 and 2). During the first 3 weeks of growth, sunn hemp produces higher leaf than stem dry matter; but by 6 weeks after planting, stem dry matter is reported to be greater than that contributed by the leaves (Mansoer et al., 1997). However, the contribution of the leaf to the biomass can be manipulated by pruning the main stem (Abdul-Baki et al., 2001). Hence, these results showing allelopathic qualities for all tissues tested suggest that all biomass from this species could potentially be used for weedsuppression purposes, but leaf tissue could be the most useful for using the allelochemical potential.

All 14 accessions of sunn hemp had strong allelopathic potential in our tests, although some accessions had greater inhibitory effects than others (Fig. 2). Together these results suggest evolution of allelochemicals in this species was an ancient one, perhaps predating speciation. The results are useful for choosing accessions with higher or lower allelopathic potentials, a critical decision in sustainable crop management. In addition, the information will be useful to breed new cultivars with enhanced or reduced allelochemical content.

Water-soluble allelochemicals were stable for a boiling treatment and acid hydrolysis and could bind and elute from ion-exchange resins (Fig. 3). Such stability is important for using the allelopathic potential of this species for weed suppression in the field. The results also suggest methods to purify and store the active principles for such applications.

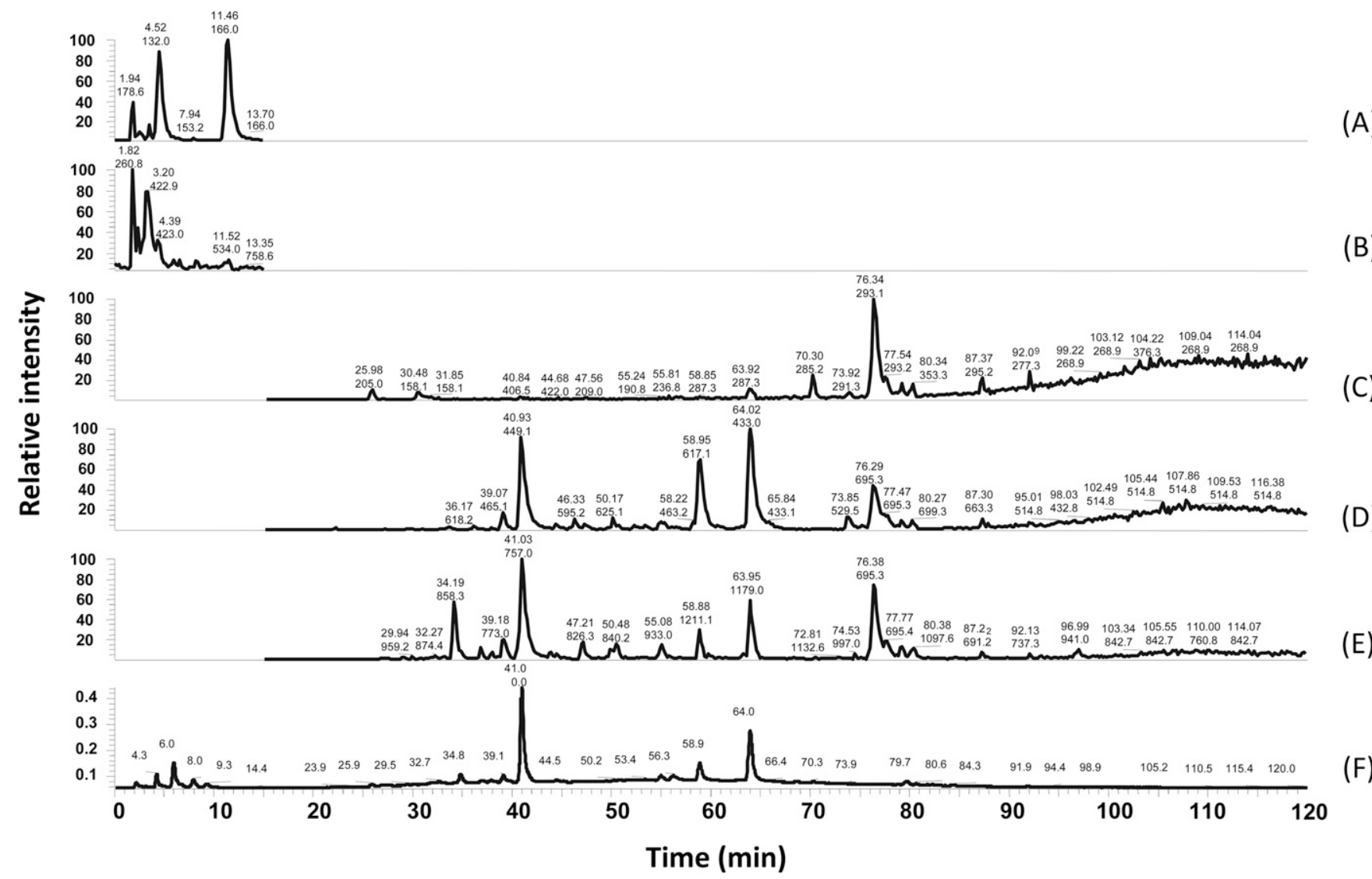

Fig. 5. Mass spectral analyses of leaf eluate from sunn hemp IN-86 under (+)ESI (electrospray ionization, positive ion mode). Mass spectral peaks in fractions eluting at different times are shown with their elution time in minutes and mass-to-charge ratio (m/z) values in m/z ranges of 125 to 200 (A), 190 to 800 (B), 125 to 430 (C), 420 to 700 (D), and 690 to 1300 (E). The ultraviolet-analog peak chromatogram from the high-performance liquid chromatography is shown in (F). 


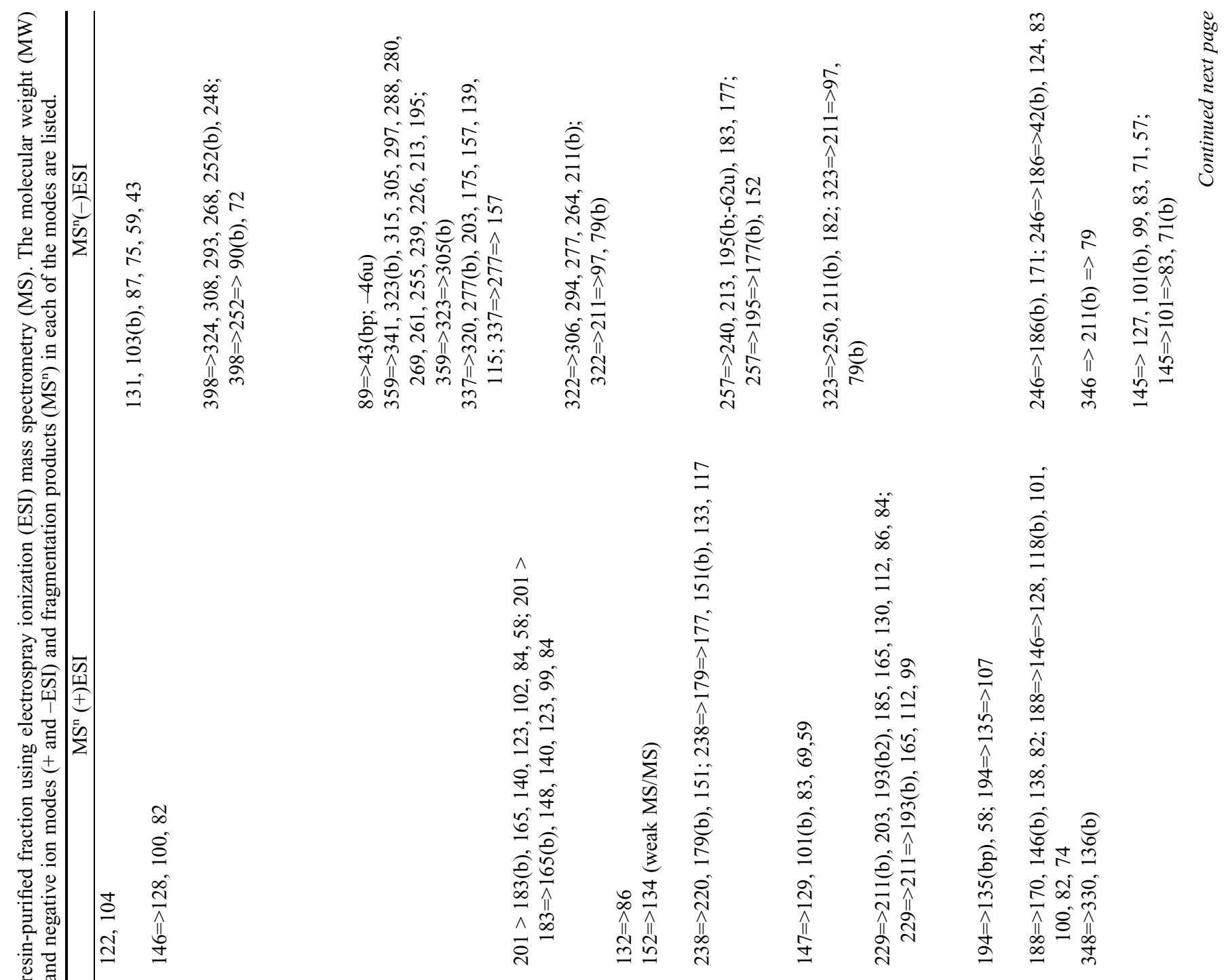

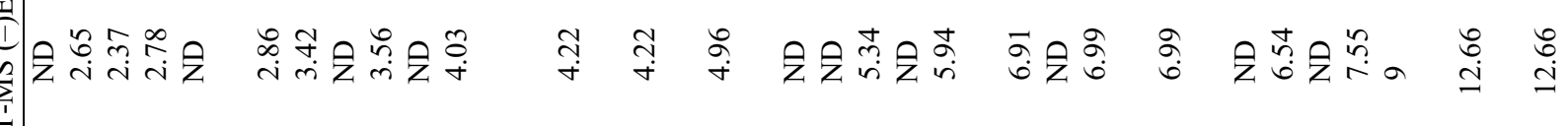

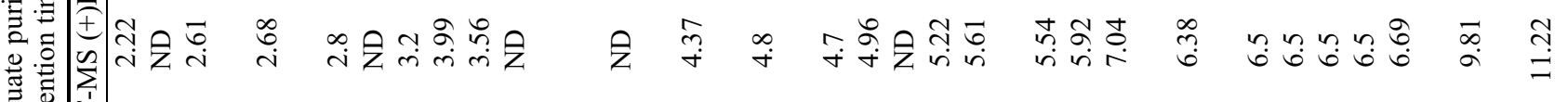
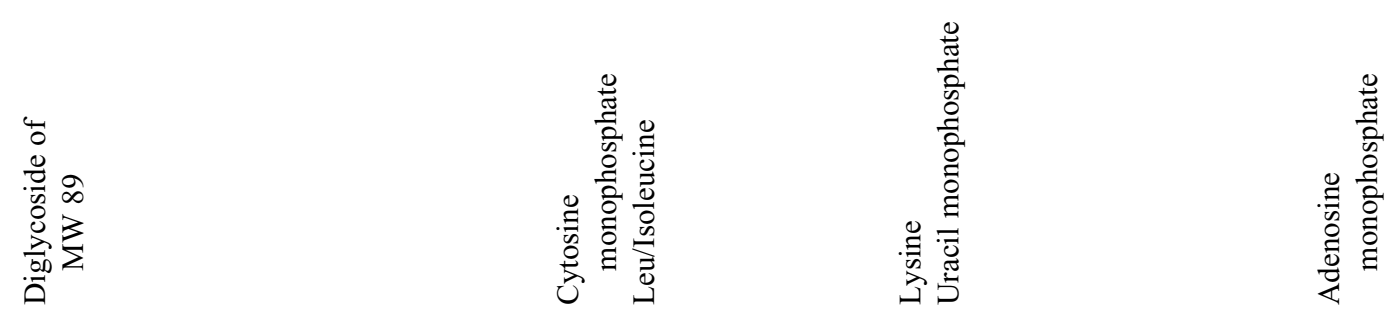


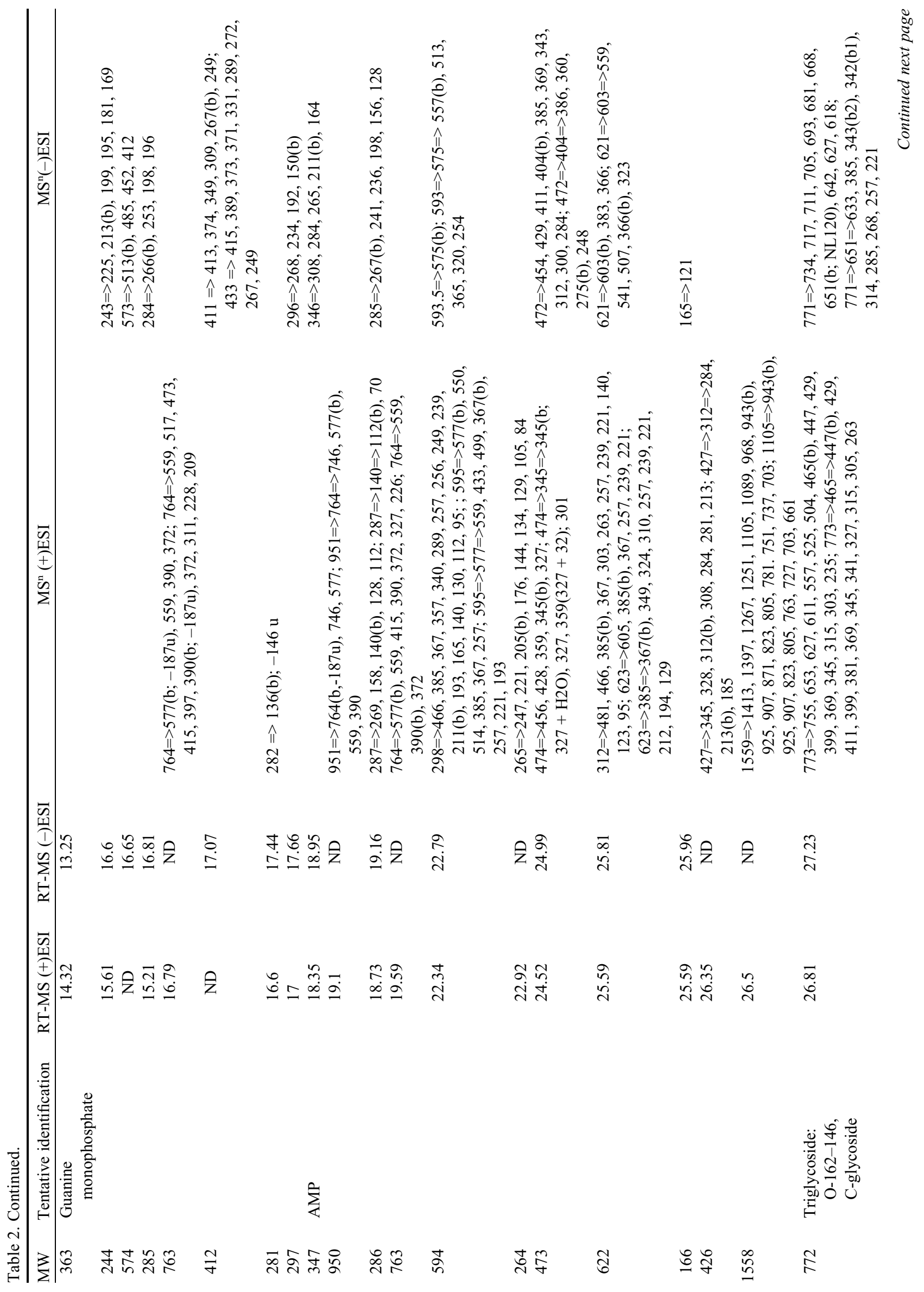




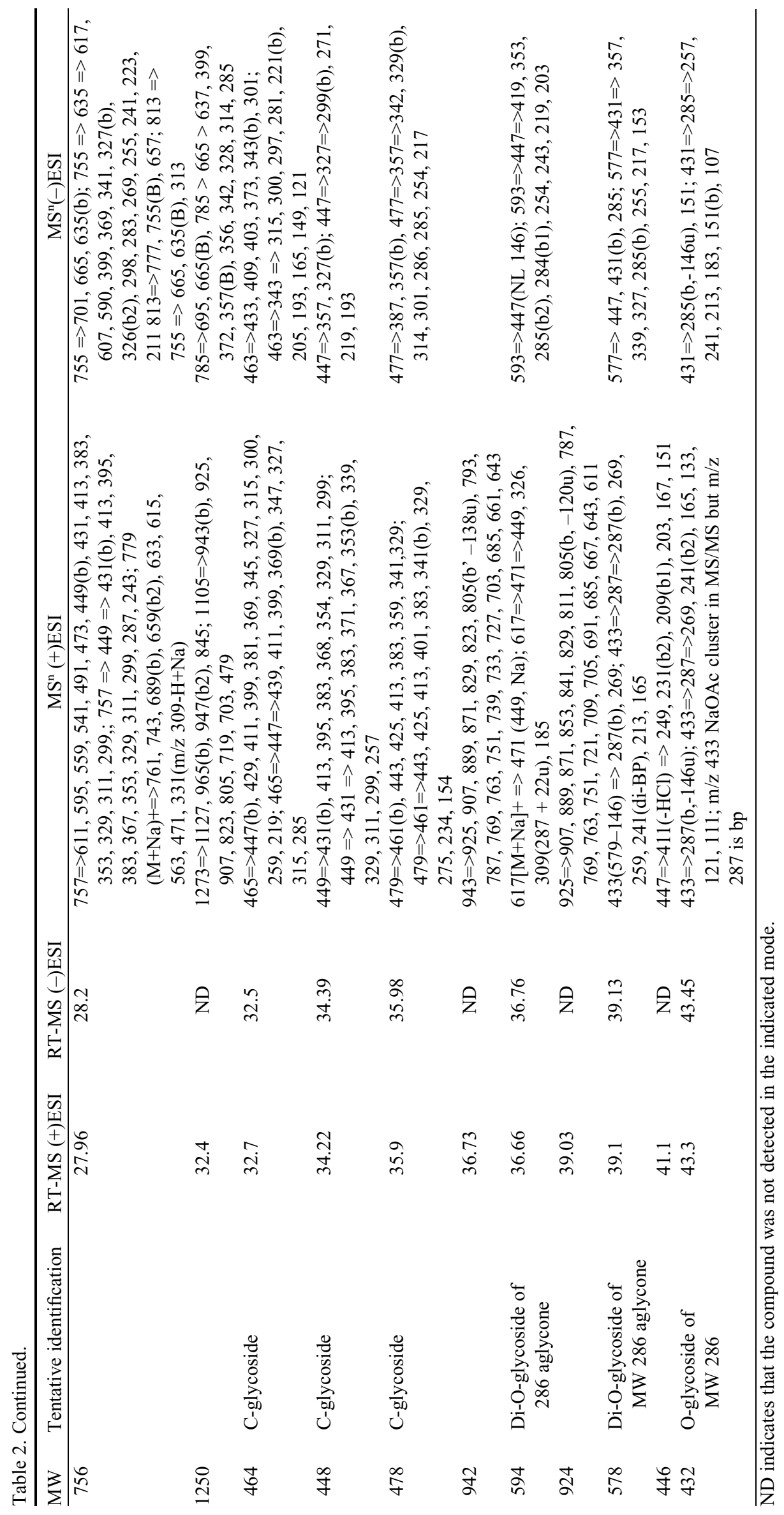




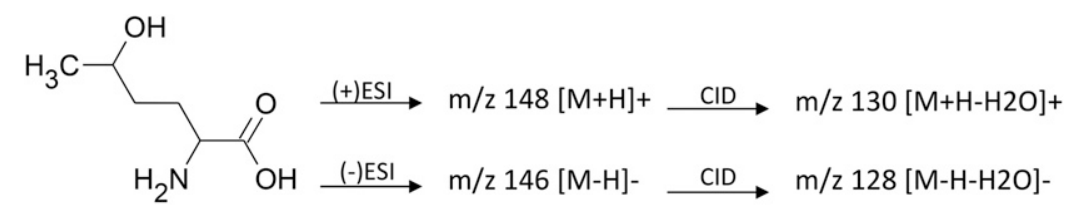

ס-hydroxynorleucine

Molecular formula $=\mathrm{C}_{6} \mathrm{H}_{13} \mathrm{NO}_{3}$

Monoisotopic mass $=147.089543 \mathrm{u}$

Fig. 6. Identification of $\delta$-hydroxynorleucine using mass spectrometry. With (+)ESI-MS (electrospray ionization mass spectrometry, positive ion mode), $\delta$-hydroxynorleucine readily forms a mass-tocharge ratio $(\mathrm{m} / \mathrm{z})$ of $148[\mathrm{M}+\mathrm{H}]+$, which upon collision-induced dissociation (CID) produced the $\mathrm{m} / \mathrm{z} 130[\mathrm{M}+\mathrm{H}-\mathrm{H} 2 \mathrm{O}]+$ product ion. With (-)ESI-MS (electrospray ionization mass spectrometry, negative ion mode), $\delta$-hydroxynorleucine forms an m/z $146[\mathrm{M}-\mathrm{H}]-$ ion, which upon CID results in an $\mathrm{m} / \mathrm{z} 128$ product due to loss of $\mathrm{H}_{2} \mathrm{O}$. Loss of $46 \mathrm{u}$ and $44 \mathrm{u}$ from the $[\mathrm{M}+\mathrm{H}]+$ and $[\mathrm{M}-\mathrm{H}]-$ ions, respectively, as shown in the figure are common for amino acids.

While chemical identification of the allelochemicals in sunn hemp leaf tissue was beyond the scope of this study, because elutions from the anion exchange resin and zwitterionic compounds had inhibitory effects in the lettuce bioassay, the inhibitory compounds could be amino acids and their derivatives including alkaloids, flavonoids, carotenoids, and phenolic compounds. The HPLC-MS-MS analysis of leaf eluates showed that the $\mathrm{m} / \mathrm{z}$ value and its product ions consistent with the presence of delta-hydroxynorleucine could be identified in such fractions (Fig. 6). However, deltahydroxynorleucine was identified to be only a minor component in the leaf eluate (i.e., $0.9 \mu \mathrm{g} \cdot \mathrm{mL}^{-1}$ ) a comparatively low concentration for allelopathy. Since delta-hydroxynorleucine is highly soluble in water, the extraction method used should have been successful in eluting it. The eluates were kept in cold storage or analyzed immediately after preparation, reducing probability of degradation. Therefore, it is likely that the phytotoxicity observed in aqueous eluates of sunn hemp leaves is due to compounds other than the nonprotein amino acid deltahydroxynorleucine, which was previously isolated from seeds of sunn hemp (Pant and Fales, 1974; Pilbeam and Bell, 1979) and shown to be inhibitory to lettuce (Wilson and Bell, 1979). The yield reported in the seeds after an isolation procedure was $1.47 \mathrm{mg} \cdot \mathrm{g}^{-1}$ seeds (Pilbeam and Bell, 1979) and the concentration we found is equivalent to about $4.5 \mu \mathrm{g} \cdot \mathrm{g}^{-1}$ leaves. Future studies should examine the contributions of differences in tissue distribution and extraction methods in estimating this nonprotein amino acid in sunn hemp. However, our results indicate that when sunn hemp biomass is incorporated into the soil, some delta-hydroxynorleucine is added. Nonprotein amino acids form a significant store of organic nitrogen in many ecosystems (Vranova et al., 2011) and the contribution of such organic nitrogen to the soil by cover crops and their ramifications for the soil ecosystem are currently not well understood. Nonprotein amino acids could favorably be used as sources of nitrogen by certain groups of microbial flora and fauna and likely affect the abundance of weed seeds and soil-borne arthropods, pathogens, and nematodes.

As expected, HPLC-MS-MS analysis of leaf eluates of sunn hemp indicated a complex profile (Fig. 4 and 5). A recent study on the leaf eluates of sunn hemp cultivar Tropic Sun indicated the presence of dehydropyrrolizidine alkaloids (Colegate et al., 2012). These alkaloids had $\mathrm{M}+\mathrm{H} \mathrm{m} / \mathrm{z}$ values of 284 (hemijunceine and its isoforms), 370 (junceine and trichodesmine $N$-oxide), 386 (junceine $\mathrm{N}$-oxide), 336 (senecionine),
326 (acetylisohemijunceine), 300 (isohemijunceine), and several partially identified compounds (Colegate et al., 2012). However, none of these $\mathrm{m} / \mathrm{z}$ values matched the $\mathrm{m} / \mathrm{z}$ values of ions that were observed in the analyses of this study done under ESI-MSMS positive ion mode. Colegate et al. (2012) used methanol for extraction of different tissue samples, and enriched their fractions for alkaloids using cation-exchange chromatography before their analyses by MS while in this study the focus was only on water-soluble compounds. Differences in the germplasm used between the two studies and methodologies in the preparation of the samples could be reasons for the differences in the mass spectral profiles.

The use of plants with allelopathic properties or bioherbicides derived from such plants for weed suppression can be used to improve the sustainability of weed management in horticultural crops. Research on both the biological and chemical properties of phytochemicals in such plants is crucial for understanding their usefulness for weed management. Sunn hemp provides multiple agroecosystem services including as a cover crop with green manure, nematode deterrence, and has potential for use as a bioenergy feedstock. The present study provided evidence for allelopathic potential in 14 accessions of sunn hemp with the strongest inhibition of lettuce germination occurring with the IN-86, NG-71, and BR-20 accessions from India, Nigeria, and Brazil, respectively. Phytotoxic compounds were stable after chemical characterization procedures suggesting potential for use in developing formulations of natural herbicides that could be employed for weed management in organic and sustainable production systems.

\section{Literature Cited}

Abdul-Baki, A.A., H.H. Bryan, G. Zinati, W. Klassen, M. Codallo, and N. Heckert. 2001. Biomass yield and flower production in sunn hemp: Effects of cutting the main stem. J. Veg. Crop Production 7:83-104.

Adler, M.J. and C.A. Chase. 2007. Comparison of the allelopathic potential of leguminous summer cover crops: Cowpea, sunn hemp, and velvetbean. HortScience 42:289-293.

Bertin, C., R. Harmon, M. Akaogi, J.D. Weidenhamer, and L.A. Weston. 2009. Assessment of the phytotoxic potential of m-tyrosine in laboratory soil bioassays. J. Chem. Ecol. 35:1288-1294.

Cole, S.D. 1991. Allelopathic effects of Crotalaria juncea, MA thesis, Univ. South Dakota, Vermillion, SD.

Colegate, S.M., D.R. Gardner, R.J. Joy, J.M. Betz, and K.E. Panter. 2012. Dehydropyrrolizidine alkaloids, including monoesters with an unusual esterifying acid, from cultivated Crotalaria juncea (sunn hemp cv. 'Tropic Sun'). J. Agr. Food Chem. 60:3541-3550.

Collins, A.S., C.A. Chase, W.M. Stall, and C.M. Hutchinson. 2008. Optimum densities of three leguminous cover crops for suppression of smooth pigweed (Amaranthus hybridus). Weed Sci. 56:753-761. Collins, A.S., C.A. Chase, W.M. Stall, and C.M. Hutchinson. 2007. Competitiveness of three leguminous cover crops with yellow nutsedge (Cyperus esculentus) and smooth pigweed (Amaranthus hybdridus). Weed Sci. 55:613-618.

Cook, C.G. and G.A. White. 1996. Crotalaria juncea: A potential multi-purpose fiber crop, p. 389-394. In: J. Janick (ed.). Progress in new crops. ASHS Press, Arlington, VA.

Cruz-Silva, C.T.A., E.B. Matiazzo, F.P. Pacheco, and L.H.P. Nóbrega. 2015. Allelopathy of Crotalaria juncea L. aqueous extracts on germination and initial development of maize. IDESIA 33(1):27-32. 
Ferguson, J.J., B. Rathinasabapathi, and M. Gal. 2004. A method to screen weed-suppressing allelochemicals in Florida biomass. Proc. Florida State Hort. Soc. 117:231-233.

Mansoer, Z., D.W. Reeves, and C.W. Wood. 1997. Sustainability of sunn hemp as an alternative late-summer legume cover crop. Soil Sci. Soc. Amer. J. 61:246-253.

Nishihara, E., M.M. Parvez, H. Araya, S. Kawashima, and Y. Fujii. 2005. L-3-(3,4-Dihydroxyphenyl)alanine (L-DOPA), an allelochemical exuded from velvetbean (Mucuna pruriens) roots. Plant Growth Regulat. 45:113-120.

Ohdan, H., H. Diamon, and H. Mimoto. 1995. Evaluation of allelopathy in Crotalaria by using a seed pack growth pouch. Jpn. J. Crop. Sci. 64:644-649.

Pant, R. and H.M. Fales. 1974. Occurrence of a new amino acid in Crotalaria seeds. Phytochemistry 13:1626-1627.

Pilbeam, D.J. and E.A. Bell. 1979. A reappraisal of the free amino acids in seeds of Crotalaria juncea (Leguminosae). Phytochemistry 18:320-321.
Rathinasabapathi, B., J. Ferguson, and M. Gal. 2005. Evaluation of allelopathic potential of wood chips for weed suppression in horticultural production systems. HortScience 40:711-713.

Skinner, E.M., J.C. Diaz-Perez, S.C. Phatak, H.H. Shomberg, and W. Vencill. 2012. Allelopathic effects of sunnhemp (Crotalaria juncea L.) on germination of vegetables and weeds. HortScience 47:138-142.

Vranova, V., K. Rejsek, K.R. Skene, and P. Formanek. 2011. Nonprotein amino acids: Plant, soil and ecosystem interactions. Plant Soil 342:31-48.

Wang, M.L., J.A. Mosjidis, R.E. Morris, T.M. Dean, and G.A. Pederson. 2006. Genetic diversity of Crotalaria germplasm assessed through phylogenetic analysis of EST-SSR markers. Genome 49:707-715.

Williams, R.D. and R.E. Hoagland. 2007. Phytotoxicity of mimosine and albizziine on seed germination and seedling growth of crops and weeds. Allelopathy J. 19:423-430.

Wilson, M.F. and E.A. Bell. 1979. Amino acids and related compounds as inhibitors of lettuce growth. Phytochemistry 18:1883-1884. 